\title{
NF-кB is a key modulator in the signaling pathway of Borrelia burgdorferi BmpA-induced inflammatory chemokines in murine microglia BV2 cells
}

\author{
ZHENYU ZHAO $^{1}$, LVYAN TAO $^{1,2}$, AIHUA LIU $^{1-6}$, MINGBIAO MA $^{1,7}$, HAIYI LI $^{8}$, HUA ZHAO $^{1}$, \\ JIARU YANG ${ }^{1}$, SHIMING WANG ${ }^{1}$, YIRONG JIN ${ }^{1}$, XIAN SHAO ${ }^{1}$ and FUKAI BAO ${ }^{1-7}$
}

${ }^{1}$ School of Basic Medical Sciences; ${ }^{2}$ Department of Biochemistry and Molecular Biology; ${ }^{3}$ Yunnan Province

Key Laboratory for Tropical Infectious Diseases in Universities; ${ }^{4}$ The Institute for Tropical Medicine;

${ }^{5}$ Yunnan Province Integrative Innovation Center for Public Health, Diseases Prevention and Control; ${ }^{6}$ Yunnan Demonstration

Base of International Science and Technology Cooperation for Tropical Diseases; ${ }^{7}$ Department of Microbiology and

Immunology; ${ }^{8}$ Faculty of Public Health, Kunming Medical University, Kunming, Yunnan 650500, P.R. China

Received May 27, 2017; Accepted November 15, 2017

DOI: $10.3892 / \mathrm{mmr} .2018 .8526$

\begin{abstract}
Lyme disease, caused by the bacterial spirochete Borrelia burgdorferi, is a tick-borne zoonosis. Lyme neuroborreliosis is a principal manifestation of Lyme disease and its pathogenesis remains incompletely understood. Recent studies have demonstrated that Borrelia burgdorferi lipoproteins caused similar inflammatory effects as exhibited in Lyme neuroborreliosis. Basic membrane protein A $(\mathrm{BmpA})$ is one of the dominant lipoproteins in the Borrelia burgdorferi membrane. In addition, nuclear factor $\kappa-\mathrm{B}(\mathrm{NF}-\kappa \mathrm{B})$ modulates the regulation of gene transcription associated with immunity and inflammation; however, in unstimulated cells, NF- $\kappa \mathrm{B}$ is combined with the inhibitor of $\mathrm{NF}-\kappa \mathrm{B}(\mathrm{I} \kappa \mathrm{B}-\beta)$. Therefore, it was hypothesized that $\mathrm{NF}-\kappa \mathrm{B}$ may be associated with BmpA-induced inflammation and the occurrence of Lyme neuroborreliosis. Therefore, the aim of the present study was to investigate the role that $\mathrm{NF}-\kappa \mathrm{B}$ serves in the signaling pathway of rBmpA-induced inflammatory chemokines. The present study measured the expression levels of NF- $\kappa B$, I $\mathrm{B}-\beta$ and inflammatory chemokines following recombinant $\mathrm{BmpA}$ (rBmpA) stimulation of murine microglia BV2 cells. Following stimulation with $\mathrm{rBmpA}$, concentrations of pro-inflammatory cytokines including $\mathrm{C}-\mathrm{X}-\mathrm{C}$ motif chemokine 2, C-C motif chemokine (CCL) 5 and CCL22 were determined by ELISA
\end{abstract}

Correspondence to: Professor Aihua Liu or Professor Fukai Bao, Yunnan Province Key Laboratory for Tropical Infectious Diseases in Universities, 1168 Chunrongxi Road, Chenggong, Kunming, Yunnan 650500, P.R. China

E-mail: lunaliu123@126.com

E-mail: bakofukai@126.com

Key words: Lyme neuroborreliosis, Borrelia burgdorferi, nuclear factor $\kappa-\mathrm{B}$, recombinant basic membrane protein A, BV2 microglia, pathogenesis analysis. Reverse transcription-quantitative polymerase chain reaction and western blotting were used to detect the expres-

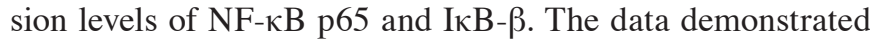
that concentrations of these chemokines in cell supernatants increased significantly following $\mathrm{rBmpA}$ stimulation. $\mathrm{NF}-\kappa \mathrm{B}$ was overexpressed, but I $\mathrm{B}-\beta$ expression was significantly decreased. In conclusion, these results suggested that $N F-\kappa B$ serves an important stimulatory role in the signaling pathway of rBmpA-induced inflammatory chemokines in BV2 cells.

\section{Introduction}

Lyme disease (LD) is a multisystem inflammatory, tick-borne disease resulting from infection with Borrelia burgdorferi $(1,2)$. LD is present in $>80$ countries, including China. A total of $\sim 3,000,000$ cases of LD are reported each year worldwide, representing an incidence of $\sim 0.111 \%(2,3)$. LD seriously affects human health, in addition to economic development. As a result, this widespread disease has been given attention regarding its prevention and treatment by the World Health Organization (3). Lyme neuroborreliosis (LNB) is a principal manifestation of LD and is caused by the inflammatory effects of the spirochete B. burgdorferi on the nervous system. LNB causes extensive neurological damage and encephalitic memory impairment, even leading to dementia and personality disorders. Given the high disability rate caused by the disease, researchers and clinicians are giving more concentrated attention to $\operatorname{LNB}(4,5)$; however, its pathogenesis remains incompletely understood. It is generally accepted that LNB is caused by an autoimmune response triggered by molecular mimicry $(6,7)$.

Microglial cells, the resident macrophage cells within the central nervous system (CNS), are important in initiating an immune response to microbial products (8). As a previous study demonstrated, CNS damage and inflammation may activate microglia (9). Reactive microglia produce various cytokines and chemokines causing an acute inflammatory reaction, which leads to neuronal damage and apoptosis. Microglia 
cells are hypersensitive to CNS damage. These cells multiply rapidly, begin to express major histocompatibility complex proteins, migrate and subsequently differentiate into phagocytes that secrete cytokines and other toxic substances $(10,11)$.

Previous studies have suggested that B. burgdorferi basic membrane protein A (BmpA), one of the primary B. burgdorferi pathogenic substances, exhibits a potent pro-inflammatory effect (11-13). In the authors' previous study, an Escherichia coli expression system was established and purified recombinant BmpA (rBmpA) was successfully obtained. When stimulated with $\mathrm{rBmpA}$, murine microglia BV2 cells produced pro-inflammatory chemokines, including $\mathrm{C}-\mathrm{X}$-C motif chemokine 2 (CXCL2), C-C motif chemokine (CCL) 5 and CCL22, causing inflammation and damage in mice (13). However, the signal transduction mechanism involved is unclear (13).

The nuclear factor $\kappa-\mathrm{B}(\mathrm{NF}-\mathrm{\kappa} \mathrm{B})$ is A protein complex which was found to specifically bind to the $\kappa B$ sequence (GGGACTTTCC) of the immunoglobulin K enhancer and regulated the expression of target genes (14-16). NF- $\mathrm{kB}$ has received widespread interest from researchers for its crucial role in the immune system. It has been demonstrated in

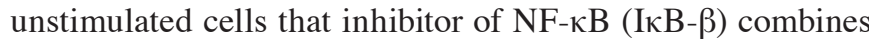
with NF- $\kappa B$ and maintains NF- $\kappa B$ an inactive state. The stimuli that cause NF- $\kappa \mathrm{B}$ activation target IкB- $\beta$ for degradation via a phosphorylation-dependent ubiquitination process $(16,17)$. With the degradation of I $\mathrm{B}-\beta, \mathrm{NF}-\kappa \mathrm{B}$ is activated, entering the cell nucleus where it encounters a promoter with DNA binding sites for NF- $\mathrm{KB}(17,18)$. The activation of target gene transcription induces the expression of specific mRNAs, and the production of cytokines and chemokines, thereby regulating the activation, multiplication, infiltration, chemotaxis and secretion of immune cells (18-20). As rBmpA stimulates the production of CXCL and CCL chemokines in microglia, it was hypothesized that NF- $\kappa B$ may be closely associated with rBmpA-induced chemokine production in BV2 cells (13).

Based on the conclusions of the authors' previous study demonstrating that rBmpA stimulates the production of inflammatory chemokines in BV2 cells, the present study continued to investigate the signal transduction mechanism of LNB (13). Additionally, the present study investigated the role of NF- $\mathrm{KB}$ in the signaling pathway of rBmpA-induced inflammatory chemokines and provides a scientific basis for the prevention and treatment of LBN.

\section{Materials and methods}

rBmpA preparation. Recombinant BmpA proteins were produced in $E$. coli using the bacterial expression vector pGEX-6P1 (GE Healthcare, Chicago, IL, USA). Expression, purification and enzymatic cleavage of the glutathione S-transferase fusion proteins were performed as previously described $(14,15)$.

Cell culture and groups. BV2 cells (Kunming Medical University Biological Engineer Center, Kunming, China) were cultured in Dulbecco's modified Eagle's medium (DMEM)/high glucose with 5\% cattle serum (CS; HyClone, Logan, UT, USA), $1 \%$ penicillin/streptomycin (Sangon Biotech Co., Ltd., Shanghai, China) at $37^{\circ} \mathrm{C}$ with $5 \% \mathrm{CO}_{2}$.
BV2 cells were seeded into a 6-well plate at a concentration of $3 \times 10^{5}$ cells $/ \mathrm{ml}$. Supernatants were discarded until the cells fully adhered to the plate. Cells were divided into three groups (negative control group, positive control group and experimental group), and were stimulated with $2 \mathrm{ml} /$ well PBS with 5\% CS-DMEM medium, $1 \mu \mathrm{g} / \mathrm{ml}$ lipopolysaccharide (LPS; Sigma-Aldrich; Merck KGaA, Darmstadt, Germany), and $20 \mu \mathrm{g} / \mathrm{ml} \mathrm{rBmpA}$, respectively. Radioimmunoprecipitation assay buffer (high; Beijing Solarbio Science \& Technology Co., Ltd., Beijing, China) was used to lyse the cells and cell lysates were collected at 12,24 and $48 \mathrm{~h}$ following stimulation.

ELISA analysis. Culture supernatants were collected at 6, 12 and $24 \mathrm{~h}$ following stimulation with $\mathrm{rBmpA}$ and were analyzed by ELISA. Mouse CXCL2 (MIP-2), mouse CCL22 (MDC) and mouse CCL5 (RANTES) ELISA kits (RayBiotech, Inc., Norcross, GA, USA; cat. nos. P10889, O88430 and P30882) was used following manufacturer's protocol. A Bio-Rad microplate reader (Model 680; Bio-Rad Laboratories, Inc., Hercules, CA, USA) was used to measure the absorbance at $450 \mathrm{~nm}$.

Reverse transcription-quantitative polymerase chain reaction (RT-qPCR) analysis. Harvested cells were lysed with RNAiso Plus (Takara Biotechnology Co., Ltd., Dalian, China) and RNA was extracted, following the manufacturer's protocol. Total RNA was reverse transcribed to cDNA. The RT-qPCR was performed using the real-time PCR System Cfx-Connect (Bio-Rad Laboratories, Inc.). The reaction conditions of the RT-qPCR were as follows: Denaturation at $95^{\circ} \mathrm{C}$ for $30 \mathrm{~min}$, annealing at $58^{\circ} \mathrm{C}$ for $1 \mathrm{~h}$ and extension at $65^{\circ} \mathrm{C}$ for $5 \mathrm{sec}$. The total volume used in the PCR was $25 \mu \mathrm{l}$, including $2 \mu \mathrm{l}$ cDNA, $12.5 \mu \mathrm{l}$ SYBR (Takara Biotechnology,

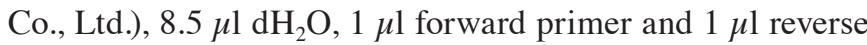
primer (Tsingke Biotech Co., Ltd., Kunming, China). The sequences of the specific primers used to amplify NF- $\mathrm{kB}$ p65 and GAPDH were as follows: NF- $\kappa$ B p 65 forward, 5'-GCT ACACAGAGGCCATTGAA-3' and reverse, 5'-TCCCGG AGTTCATCTATGTG-3'; IкB- $\beta$ forward, 5'-GGGAACGTC AGTCTGTACCA-3' and reverse, 5'-GCACCATCGCTCTCT GTTTT-3'; GAPDH forward, 5'-TCCCAGAGCTGAACG GGAAG-3' and reverse, 5'-TCAGTGGGCCCTCAGATGC-3'. The gene expression level was calculated using the method of $2^{-\Delta \Delta C q}(21-23)$.

Western blot analysis. Total protein quantitation analysis was used as the internal control for quantitative fluorescent western blot analysis (24-27). Cells were lysed in radioimmunoprecipitation lysis buffer (Beyotime Institute of Biotechnology, Haimen, China) with $1 \mathrm{mM}$ phenylmethylsulfonyl fluoride (Beyotime Institute of Biotechnology), and quantified using a bicinchoninic acid protein assay kit (Beyotime Institute of Biotechnology). Proteins were separated on 10\% TGX FastCast acrylamide gels (Bio-Rad Laboratories, Inc.) with a loading mass of $20 \mu \mathrm{g}$ total protein, then subsequently transferred to a polyvinylidene difluoride (PVDF) membranes (0.2 $\mu \mathrm{m}$; Bio-Rad Laboratories, Inc.) using Trans-Blot Turbo Transfer System (p65, $15 \mathrm{~V}$ in 4-min protocol; IkB- $\beta, 15 \mathrm{~V}$ in 4-min protocol; Bio-Rad Laboratories, Inc.) with Trans-Blot Turbo Midi Transfer 

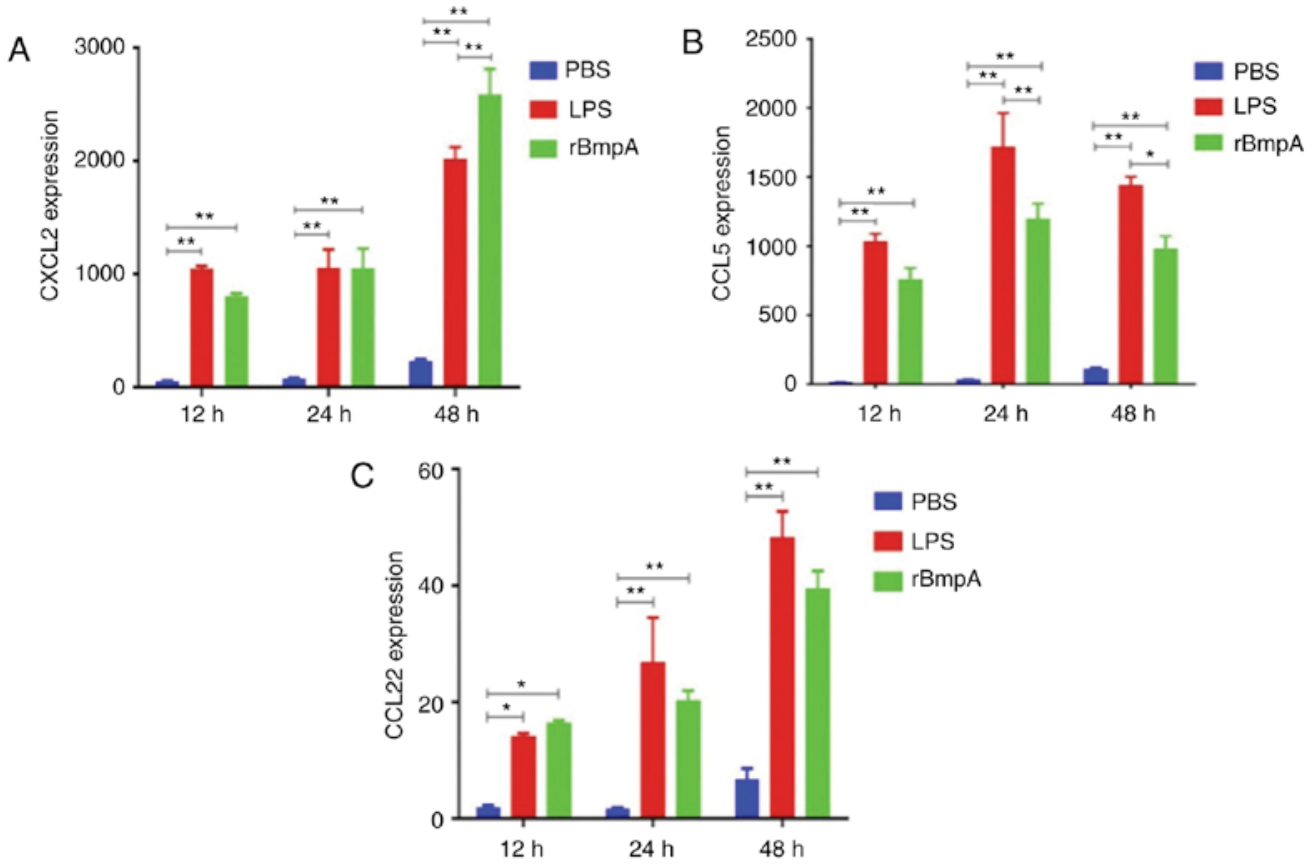

Figure 1. Analysis of the expression of inflammatory cytokines in BV2 cells. (A) CXCL2, (B) CCL5 and (C) CCL22 expression following stimulation with $20 \mu \mathrm{g} / \mathrm{ml} \mathrm{rBmpA}$ for different time periods (12, 24 and $48 \mathrm{~h})$. The experimental results exhibited are representative of three independent tests. Each value represents the mean \pm standard error of the mean. ${ }^{*} \mathrm{P}<0.05 ;{ }^{* *} \mathrm{P}<0.01$. rBmpA, recombinant basic membrane protein A; LPS, lipopolysaccharide; CXCL2, C-X-C motif chemokine 2; CCL, C-C motif chemokine.

Packs (Bio-Rad Laboratories, Inc.). The PVDF membranes were blocked with $5 \%$ skim milk at $37^{\circ} \mathrm{C}$ for $2 \mathrm{~h}$. Blots were incubated with specific primary antibodies of NF- $\kappa \mathrm{B}$ p65 (cat. no. ab16502; 1:2,000; Abcam, Cambridge, UK) or IкB- $\beta$ (cat. no. ab7574; 1:1,000; Abcam) overnight at $4^{\circ} \mathrm{C}$, and subsequently incubated with goat anti-rabbit secondary antibodies (cat. no. BS13278; p65 1:10,000; Nanjing Bioworld Biotech Co., Ltd., Nanjing, China; cat. no. ab150077; IкB- $\beta$; 1:3,000; Abcam) at room temperature for $2 \mathrm{~h}$. The blots were washed three times between the primary and secondary antibody incubations. The immunoreactive bands were imaged using an infrared imaging system (Bio-Rad Laboratories, Inc.). ChemiDoc $^{\mathrm{TM}}$ XRS+Systems with Image Lab ${ }^{\mathrm{TM}}$ software (Bio-Rad Laboratories, Inc.) was used to analyze the western blot results of NF- $\kappa \mathrm{B}$ p 65 and $\mathrm{I} \kappa \mathrm{B}-\beta$.

Statistical analysis. The results are expressed as the mean \pm standard error of the mean and were analyzed using the GraphPad Prism 6 software package (GraphPad Software, Inc., La Jolla, CA, USA) (26). Two-way analysis of variance was used to calculate the P-values, multiple comparison between the groups was performed using the Student-Newman-Keuls method. $\mathrm{P}<0.05$ was considered to indicate a statistically significant difference.

\section{Results}

rBmpA significantly stimulates the production of the inflammatory cytokines CXCL2, CCL5 and CCL22 in BV2 cells. To determine whether rBmpA induces the production of pro-inflammatory chemokines in BV2 cells, analysis of CXCL2, CCL5 and CCL22 concentrations in the cell supernatants was assayed by ELISA. The results demonstrated that rBmpA significantly increased CXCL2, CCL5 and CCL22 expression at all time points tested compared with the PBS only group $(\mathrm{P}<0.05$; Fig. 1$)$. The expression of the three chemokines demonstrated an increasing trend between 12 and $48 \mathrm{~h}$, except for a slight decline in CCL5 between 24 and $48 \mathrm{~h}$ (Fig. 1B).

rBmpA stimulation induces an increase in $N F-\kappa B$ and decrease in $I \kappa B-b m R N A$ in $B V 2$ cells. $\mathrm{rBmpA}$ stimulation significantly increased CXCL2, CCL5 and CCL22 expression compared with the PBS control $(\mathrm{P}<0.05)$. Therefore,


degradation of cytosolic I $\kappa \mathrm{B}-\beta$ was investigated. RT-qPCR was used to analyze the expression of $N F-\kappa B$ p65 and IкB- $\beta$ mRNA. As exhibited in Fig. 2, the expression of $N F-\kappa B$ mRNA in the group treated with $\mathrm{rBmpA}$ was significantly increased $(\mathrm{P}<0.01)$ compared with the PBS-only control at 12 , 24 and $48 \mathrm{~h}$ and $\mathrm{rBmpA}$ treatment significantly decreased the intracellular levels of IкB- $\beta(\mathrm{P}<0.05)$.

rBmpA stimulation induces an increase in $N F-\kappa B$ p65 and the degradation of $I \kappa B$-bproteins in BV2 cells. Western blot analysis was used to detect the protein expression levels of $\mathrm{NF}-\kappa \mathrm{B}$ p65 and I $\mathrm{B}-\beta$ in BV2 cells. As exhibited in Fig. 3, following stimulation with $\mathrm{rBmpA}$ for 12,24 and $48 \mathrm{~h}$, $\mathrm{NF}-\kappa \mathrm{B}$ p65 protein expression was significantly increased $(\mathrm{P}<0.05)$ and the protein level of $\mathrm{I} \kappa \mathrm{B}-\beta$ was significantly decreased $(\mathrm{P}<0.05)$ in the $\mathrm{rBmpA}$ treatment group compared with the PBS-only control. Increased expression levels of $\mathrm{NF}-\kappa \mathrm{B}$ p 65 protein were observed in the $\mathrm{rBmpA}$ and LPS treatment groups. $\mathrm{rBmpA}$ significantly decreased the intracellular levels of I $\mathrm{B}-\beta$ protein compared with the PBS control $(\mathrm{P}<0.05)$. 

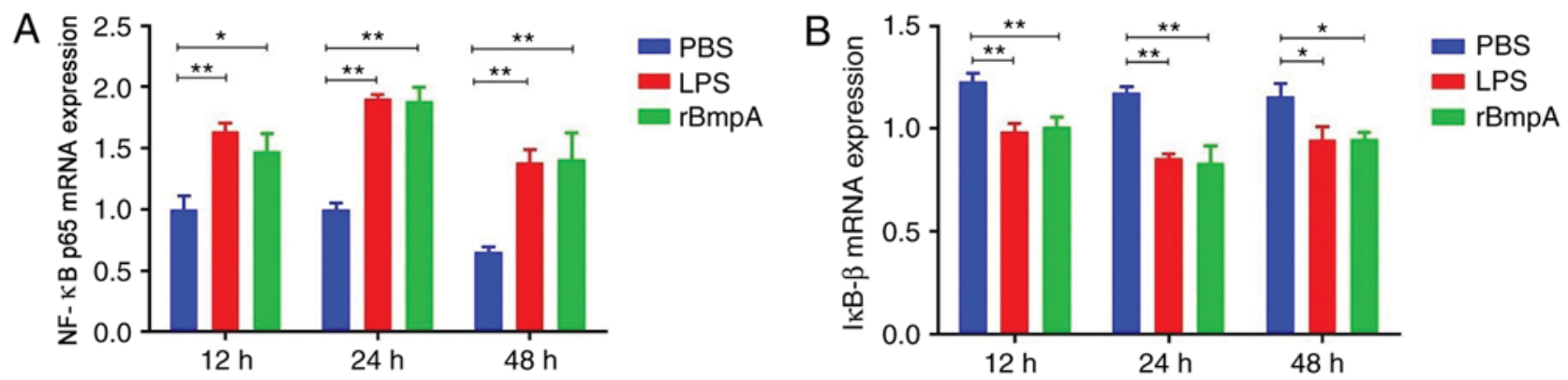

Figure 2. Time-dependent effects of rBmpA on the expression of NF- $\kappa B$ p65 and IкB- $\beta$ mRNA at $12-24 \mathrm{~h}$. BV2 microglia were stimulated by $20 \mathrm{mg} / \mathrm{ml} \mathrm{rBmpA}$ for $48 \mathrm{~h}$. The levels of (A) NF-кB p65 and (B) IкB- $\beta$ mRNA were determined by reverse transcription-quantitative polymerase chain reaction. Each value represents the mean \pm standard error of the mean. $n=3$. ${ }^{*} \mathrm{P}<0.05 ;{ }^{* *} \mathrm{P}<0.01$. NF- $\kappa \mathrm{B}$, nuclear factor $\kappa-\mathrm{B}$; rBmpA, recombinant basic membrane protein $\mathrm{A}$; IкB- $\beta$. inhibitor of NF-кB; LPS, lipopolysaccharide.
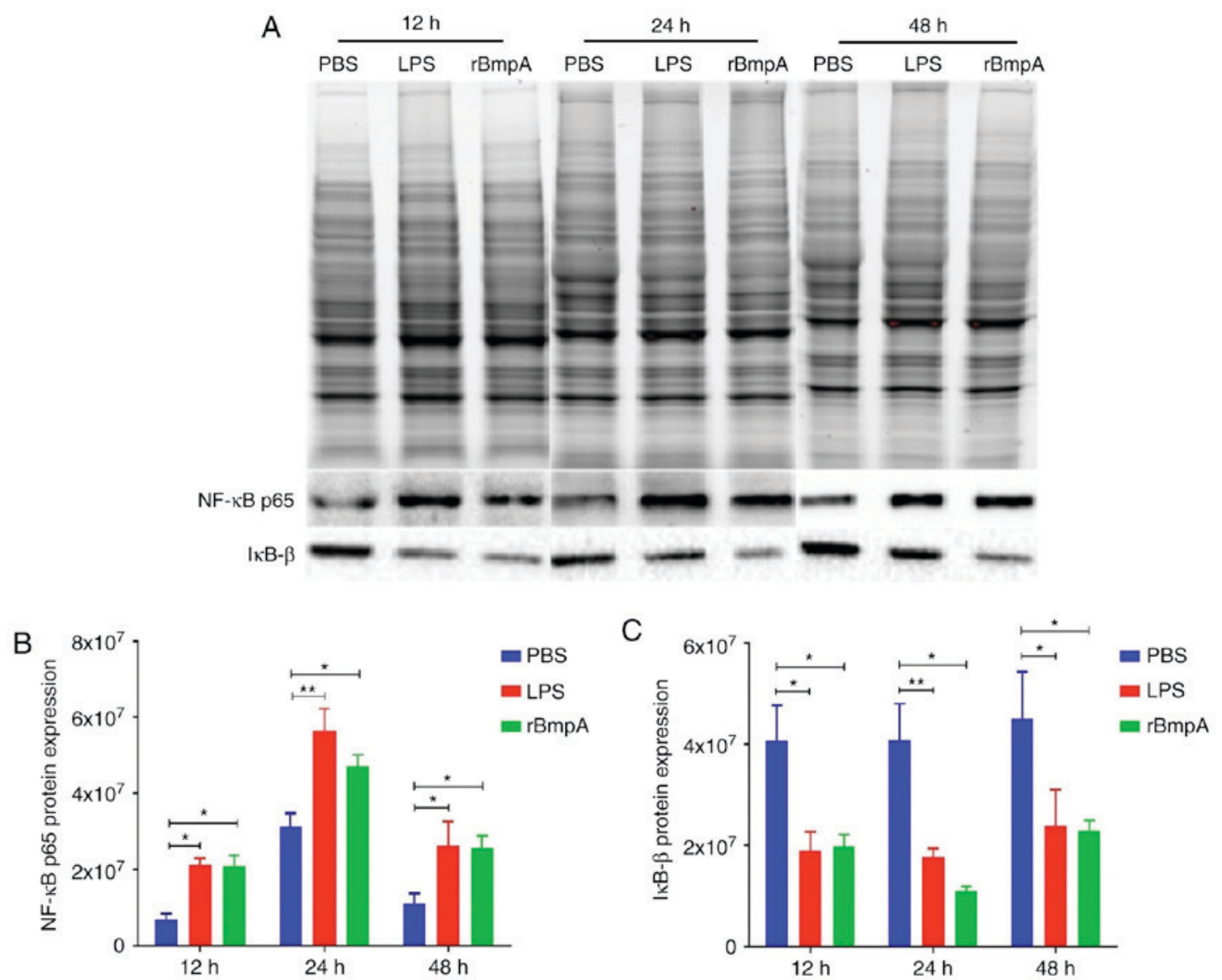

Figure 3. Total protein quantification was used to analyze the protein expression of NF- $\kappa \mathrm{B}$ p 65 and IкB- $\beta$ in BV2 cells. The cells were stimulated with $20 \mu \mathrm{g} / \mathrm{ml}$ $\mathrm{rBmpA}$ or $1 \mu \mathrm{g} / \mathrm{ml}$ LPS at different time points $(12,24$ and $48 \mathrm{~h})$. (A) The total protein was measured by SDS-PAGE using a Stain-Free Gel. The expression

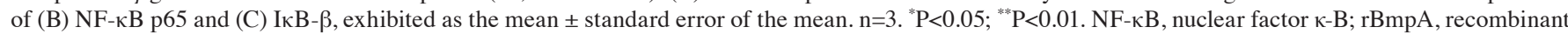
basic membrane protein A; IкB- $\beta$ inhibitor of NF-кB; LPS, lipopolysaccharide.

\section{Discussion}

$\mathrm{NF}-\kappa \mathrm{B}$ is a nuclear transcription factor which regulates the immune response, stress response and apoptosis (28). Upregulation of NF- $\mathrm{KB}$ has been demonstrated in various tumors, pulmonary disease and hepatic disease. Previous in vitro studies have suggested that NF- $\mathrm{kB}$ is a key signal transduction molecule in the downstream pathway of Toll-like receptors (TLRs) $(29,30)$. Once the TLRs are stimulated by various pathogenic factors, the degradation of IкB- $\beta$ is initiated and NF- $\mathrm{KB}$ is free to enter the cell nucleus, where NF-кB combines with the IкB motif controlling the transcription of a number of cytokines, including tumor necrosis factor- $\alpha$ (TNF- $\alpha)$, CXCL13 and interleukin (IL)-6. Studies have demonstrated that NF- $\mathrm{kB}$ is a transducer of various common inflammatory signaling pathway reactions (27-30). Therefore, methods of inhibiting NF- $\kappa B$ signaling have potential therapeutic applications in inflammatory diseases. At present, a number of anti-inflammatory drugs and anti-rheumatic drugs, including corticosteroids and aspirin, have been confirmed to be inhibitors of NF- $\mathrm{KB}$ activation $(31,32)$. 
It has been reported that the $B$. burgdorferi $b m p A / B$ gene operon exhibits the most marked upregulation in mouse and human joints (33). BmpA possesses stimulatory activity through functional domains that trigger the inflammatory response. For example, the activated NF- $\kappa \mathrm{B}$ kinase signalling pathway in articular synovial cells was demonstrated to produce pro-inflammatory cytokines including TNF- $\alpha$ and IL-1 $\beta$, triggering prostaglandin E2 receptor EP4 subtype (PGE-2) (15,34). Rasley et al (35) confirmed that $B$. burgdorferi was an important stimulus that induced microglia to produce IL-6, TNF- $\alpha$ and PGE-2, which was associated with increased expression of NF- $\kappa \mathrm{B}$, TLR2 and cluster of differentiation 14 in BV2 cells. By activating signaling molecules, B. burgdorferi stimulated immune cells to produce multiple inflammatory substances (35). Further investigation by Sun et al (36) suggested that substance $\mathrm{P}$ was able to prompt $B$. burgdorferi-induced $\mathrm{NF}-\kappa \mathrm{B}$ activation by upregulating $\mathrm{NF}-\kappa \mathrm{B}$ subunit p65, causing a significant increase in the production of inflammatory cytokines (36). NF- $\kappa \mathrm{B}$ serves an important role in the inflammatory cytokine signaling pathway of immune cells. However, $\mathrm{rBmpA}$ and NF- $\mathrm{BB}$ associated pathogenesis in $\mathrm{LNB}$, to the best of the authors' knowledge, has not been reported in the literature. A recent report indicated that $\mathrm{rBmpA}$ induced activation of BV2 cells with a concentration-dependent secretion of inflammatory chemokines (13). Therefore, rBmpA may be associated with the inflammatory chemokines produced by BV2 cells and the occurrence of LNB. However, the precise mechanism of the signal transduction pathway remains uncertain.

In the present study, whether $\mathrm{NF}-\kappa \mathrm{B}$ was a key modulator in the inflammatory chemokines (CXCL2, CCL5 and CCL22) signaling pathway stimulated by $\mathrm{rBmpA}$ in BV2 cells was investigated. The results of the present study demonstrated that CXCL2, CCL5, CCL22, NF- $\kappa \mathrm{B}$ mRNA and NF- $\kappa \mathrm{B}$ protein increased and the protein and mRNA levels of I $\kappa \mathrm{B}-\beta$ decreased following stimulation with $\mathrm{rBmpA}$ in BV2 cells. It was demonstrated that $\mathrm{NF}-\kappa \mathrm{B}$ served a key role in the signaling pathways stimulated by $\mathrm{rBmpA}$ in BV2 cells, resulting in the production of various inflammatory chemokines. This result increases the understanding of the pathogenesis of LNB. Future studies will investigate the key proteins in inflammatory chemokine signaling pathways stimulated by $\mathrm{rBmpA}$ and, most importantly, investigate whether these signaling pathways also modulate the pathogenesis of Lyme arthritis, dermatitis and carditis. The long-term aim is to investigate whether preventive and therapeutic medicines for LNB may be developed that target these proteins (37).

In conclusion, following stimulation by $\mathrm{rBmpA}$, BV2 cells overexpressed $\mathrm{NF}-\kappa \mathrm{B}$ and exhibited significantly reduced expression of $\mathrm{I} \kappa \mathrm{B}-\beta$ in the inflammatory cytokine-signaling pathway. This result suggested that $N F-\kappa B$ is important in the inflammatory cytokines signaling pathways stimulated by rBmpA and may be associated with the occurrence of LNB. The present study further clarified the mechanism underlying the rBmpA-induced inflammatory chemokines signaling pathway in microglial cells, and provides a scientific basis for the prevention and treatment of LNB.

\section{Acknowledgements}

The present study was supported by the National Natural Science Foundation of China (grant nos. 81560596 and 3156005) and the
Natural Foundation of Yunnan Province (grant nos. 2012FB011, 2014FA011, 2014FB001 and 2017FE467-001).

\section{References}

1. Borchers AT, Keen CL, Huntley AC and Gershwin ME: Lyme disease: A rigorous review of diagnostic criteria and treatment. J Autoimmun 57: 82-115, 2015

2. Pal U, Wang P, Bao F, Yang X, Samanta S, Schoen R, Wormser GP, Schwartz I and Fikrig E: Borrelia burgdorferi basic membrane proteins $\mathrm{A}$ and $\mathrm{B}$ participate in the genesis of Lyme arthritis. J Exp Med 205: 133-141, 2008.

3. Ramamoorthi N, Narasimhan S, Pal U, Bao F, Yang XF, Fish D, Anguita J, Norgard MV, Kantor FS, Anderson JF, et al: The Lyme disease agent exploits a tick protein to infect the mammalian host. Nature 436: 573-577, 2005.

4. Lantos PM, Shapiro ED, Auwaerter PG, Baker PJ, Halperin JJ, McSweegan E and Wormser GP: Unorthodox alternative therapies marketed to treat Lyme disease. Clin Inf Dis 60: 1776-1782, 2015.

5. Marques AR: Lyme neuroborreliosis. Continuum (Minneap Minn) 21 (6 Neuroinfectious Disease): 1729-1744, 2015.

6. Bremell D and Dotevall L: Oral doxycycline for Lyme neuroborreliosis with symptoms of encephalitis, myelitis, vasculitis or intracranial hypertension. Eur J Neurol 21: 1162-1167, 2014.

7. Cerar T, Ogrinc K, Lotričfurlan S, Lotric-Furlan S, Kobal J, Levicnik-Stezinar S, Strle F and Ruzić-Sabljic E: Diagnostic value of cytokines and chemokines in Lyme neuroborreliosis. Clin Vaccine Immunol 20: 1578-1584, 2013.

8. Kim C, Cho ED, Kim HK, You S, Lee HJ, Hwang D and Lee SJ: $\beta 1$-integrin-dependent migration of microglia in response to neuron-released $\alpha$-synuclein. Exp Mol Med 46: e91, 2014.

9. Togna AR, Latina V, Trefiletti G, Guiso M, Moschini S and Togna GI: 1-Phenil-6,7-dihydroxy-isochroman inhibits inflammatory activation of microglia. Brain Res Bull 95: 33-39, 2013.

10. Brissette CA, Houdek HM, Floden AM and Rosenberger TA: Acetate supplementation reduces microglia activation and brain interleukin-1 $\beta$ levels in a rat model of Lyme neuroborreliosis. J Neuroinflammation 9: 249, 2012.

11. Kuhlow CJ, Garcia-Monco JC, Coleman JL and Benach JL: Murine microglia are effective phagocytes for Borrelia burgdorferi. J Neuroimmunol 168: 183-187, 2005.

12. Battisti JM, Bono JL, Rosa PA, Schrumpf ME, Schwan TG and Policastro PF: Outer surface protein A protects Lyme disease spirochetes from acquired host immunity in the tick vector. Infect Immun 76: 5228-5237, 2008.

13. Zhao H, Liu A, Cui Y, Liang Z, Li B and Bao F: Borrelia burgdorferi basic membrane protein A could induce chemokine production in murine microglia cell line BV2. Microb Pathog 111: 174-181, 2017.

14. Simpson WJ, Schrumpf ME and Schwan TG: Reactivity of human Lyme borreliosis sera with a 39-kilodalton antigen specific to Borrelia burgdorferi. J Clin Microbiol 28: 1329-1337, 1990.

15. Yang X, Izadi H, Coleman AS, Wang P, Ma Y, Fikrig E, Anguita J and $\mathrm{Pal} \mathrm{U}$ : Borrelia burgdorferi lipoprotein $\mathrm{BmpA}$ activates pro-inflammatory responses in human synovial cells through a protein moiety. Microbes Infect 10: 1300-1308, 2008.

16. Baldwin AS Jr: The NF-kappa B and I kappa B proteins: New discoveries and insights. Annu Rev Immunol 14: 649-683, 1996.

17. Whiteside ST, Epinat JC, Rice NR and Israël A: I kappa B epsilon, a novel member of the I kappa B family, controls RelA and cRel NF-kappa B activity. EMBO J 16: 1413-1426, 1997.

18. Bell S, Degitz K, Quirling M, Jilg N, Page S and Brand K: Involvement of NF-kappaB signaling in skin physiology and disease. Cell Signal 15: 1-7, 2003.

19. Vinayagamoorthi R, Koner BC, Kavitha S, Nandakumar DN, Padma Priya P and Goswami K: Potentiation of humoral immune response and activation of NF-kappaB pathway in lymphocytes in experimentally induced hyperthyroid rats. Cell Immunol 238: 56-60, 2005.

20. Colleran A, Collins PE and Carmody RJ: Assessing Sites of NF- $\kappa \mathrm{B}$ DNA binding using chromatin immunoprecipitation. Methods Mol Biol 1280: 47-59, 2015. 
21. Leal VO, Saldanha JF, Stockler-Pinto MB, Cardozo LF, Santos FR, Albuquerque AS, Leite M Jr and Mafra D: NRF2 and NF- $\kappa$ B mRNA expression in chronic kidney disease: A focus on nondialysis patients. Int Urol Nephrol 47: 1985-1991, 2015.

22. Naranjo V, Ayllón N, Pérez de la Lastra JM, Galindo RC, Kocan KM, Blouin EF, Mitra R, Alberdi P, Villar M and de la Fuente J: Reciprocal regulation of NF-kB (Relish) and subolesin in the tick vector, Ixodes scapularis. PLoS One 8: e65915, 2013.

23. Irvine M, Okitsu C and Hsieh CL: Q-PCR in combination with ChIP assays to detect changes in chromatin acetylation. Methods Mol Biol 791: 213-223, 2011.

24. Eaton SL, Roche SL, Llavero Hurtado M, Oldknow KJ, Farquharson C, Gillingwater TH and Wishart TM: Total protein analysis as a reliable loading control for quantitative fluorescent western blotting. PLoS One 8: e72457, 2013.

25. G5: ding Control for Quantitative Fluorescent Western Blotting. Plos One 8: e72457, 2013.238: 56-605, 2097. and brain interleukin-1 $\beta$ lev.

26. Vigels $\varnothing$ A, Dybboe R, Hansen CN, Dela F, Helge JW and Guadalupe Grau A: GAPDH and $\beta$-actin protein decreases with aging, making stain-free technology a superior loading control in Western blotting of human skeletal muscle. J Appl Physiol (1985) 118: 386-394, 2015.

27. Rivero-Gutiérrez B, Anzola A, Martínez-Augustin O and de Medina FS: Stain-free detection as loading control alternative to Ponceau and housekeeping protein immunodetection in Western blotting. Anal Biochem 467: 1-3, 2014.

28. Ruzehaji N, Avouac J, Elhai M, Frechet M, Frantz C, Ruiz B, Distler JH and Allanore Y: Combined effect of genetic background and gender in a mouse model of bleomycin-induced skin fibrosis. Arthritis Res Ther 17: 145, 2015.

29. Peri S, Devarajan K, Yang DH, Knudson AG and Balachandran S Meta-analysis Identifies NF- $\mathrm{BB}$ as a therapeutic target in renal cancer. PLoS One 8: e76746, 2013.

30. Murqueitio MS, Ebner S, Hörtnagl P, Rakers C, Bruckner R, Henneke P, Wolber G and Santos-Sierra S: Enhanced immunostimulatory activity of in silico discovered agonists of Toll-like receptor 2 (TLR2). Biochim Biophys Acta 1861: 2680-2689, 2017.
31. Ottonello L, Bertolotto M, Montecucco F, Bianchi G and Dallegri F: Delayed apoptosis of human monocytes exposed to immune complexes is reversed by oxaprozin: Role of the Akt/IkappaB kinase/nuclear factor kappaB pathway. Br J Pharmacol 157: 294-306, 2009.

32. Carvalho L, Jacinto A and Matova $\mathrm{N}$ : The toll/NF- $\kappa \mathrm{B}$ signaling pathway is required for epidermal wound repair in Drosophila. Proc Natl Acad Sci USA 111: E5373-E5382, 2014.

33. Baum E, Hue F and Barbour AG: Experimental infections of the reservoir species Peromyscus leucopus with diverse strains of Borrelia burgdorferi, a Lyme disease agent. MBio 3: e00434-12, 2012.

34. Bernardino AL, Myers TA, Alvarez X, Hasegawa A and Philipp MT: Toll-like receptors: Insights into their possible role in the pathogenesis of lyme neuroborreliosis. Infect Immun 76: 4385-4395, 2008.

35. Rasley A, Marriott I, Halberstadt CR, Bost KL and Anguita J: Substance $\mathrm{P}$ augments Borrelia burgdorferi-induced prostaglandin E2 production by murine microglia. J Immunol 172: 5707-5713, 2004.

36. Sun J, Ramnath RD, Zhi L, Tamizhselvi R and Bhatia M: Substance P enhances NF-kappaB transactivation and chemokine response in murine macrophages via ERK1/2 and p38 MAPK signaling pathways. Am J Physiol Cell Physiol 294: C1586-C1596, 2008.

37. Sadik CD, Hunfeld KP, Bachmann M, Kraiczy P, Eberhardt W, Brade V, Pfeilschifter J and Mühl H: Systematic analysis highlights the key role of TLR2/NF-kappaB/MAP kinase signaling for IL-8 induction by macrophage-like THP-1 cells under influence of Borrelia burgdorferi lysates. Int $\mathrm{J}$ of Biochem Cell Biol 40: 2508-2521, 2008.

This work is licensed under a Creative Commons

Attribution-NonCommercial-NoDerivatives 4.0 International (CC BY-NC-ND 4.0) License. 